\title{
Ripple Control in AC to DC Converter
}

\author{
Sudeep Pyakuryal ${ }^{1}$, Mohammad Matin ${ }^{3}$ \\ Department of Electrical and Computer Engineering University of Denver
}

\begin{abstract}
When a sinusoidal voltage is converted into dc, the output voltage waveform inherently contains ripples. Ripple is an unwanted ac component in dc output. Smaller value of ripple factor is desirable. Ideal value of ripple factor is zero. Zero ripple factor means a perfectly dc quantity. Undesirable effects of the ripple include equipment heating, increased losses, and reduced equipment life among others. Ripple factor of a singlephase half-wave uncontrolled rectifier is 1.21 . This value is unacceptably high. To overcome the problem, a single-phase full-wave uncontrolled rectifier is proposed with a ripple factor of 0.48 .

In this paper, the ripple factor for above mentioned rectifiers with a resistive load is presented mathematically and pictorially. The rectifiers are modeled and waveforms are obtained using a computer program called Alternative Transients program, ATP. At the end, results are presented and compared. Ripple factor was improved by a factor of $40 \%$ by using a 2-pulse rectifier instead of a 1-pulse rectifier. Theoretically, if the number of pulses is increased to infinity, the ripple factor will reduce to zero giving a perfect dc output. Subsequently, 6-pulse, 12-pulse, and 18-pulse rectifiers will be modeled and advanced studies will be carried out. This paper will help understand the one of the power quality components called ripple in dc output. The paper will be useful for college seniors, graduated students, and power electronics design engineers.
\end{abstract}

Keywords: AC to DC converter, Rectifier, Diode, Ripple Factor, ATP

\section{INTRODUCTION}

Power quality components can easily be found for a sinusoidal voltage and current of same frequency. However, in power electronic, the switching devices like diodes are not on for entire cycle. The switches are on for some portion of the cycle and off for other portion. Therefore, the output waveforms from power electronic devices like rectifiers are periodic but not sinusoidal. Therefore the equations available for pure sinusoidal waveforms cannot be applied in power electronics.

To compare the performance of different types of rectifiers of the same class, an index called ripple factor is investigated in this paper in detail. It is desirable for a rectifier that the voltage and current ripple in the output waveform be as low as possible to maintain a good quality of the output. The ripple factor is ratio of root mean square (rms) value of ac component to average value of dc output [1]. The ac component of the output waveform is obtained by subtracting dc component from the output waveform [2]. Thus, mathematically

Ripple factor $=$ rms value of ac component/ average value of dc component

$$
\begin{aligned}
& =\left\{\sqrt{ }\left(\mathbf{I}^{2}{ }^{2} \mathbf{I}_{0}{ }_{0}\right)\right\} / \mathbf{I}_{0} \\
& =\sqrt{ }\left\{\left(\mathbf{I}_{/} \mathbf{I}_{0}\right)^{2}-1\right\} \\
\text { where, } & \mathbf{I}_{=} \text {RMS value of output current } \\
& \mathbf{I}_{0=} \text { Average value of output current }
\end{aligned}
$$

\section{RIPPLE EFFECTS}

Ripple quantity results in many unwanted effects in a dc system. Some of the known effects are explained below [3].

A. I ${ }^{2} R$ Loss: For a perfectly dc current, the current will be distributed uniformly across the cross-section of the conductor. However, when the current is alternating or has ac component, the current tends to concentrate closer to the conductor surface. The effect is called skin effect. Skin effect offers higher resistivity to the ripple current resulting in higher surface temperature and conductor losses.

B. Stray Heating: Ripple current induces current in the neighboring metal structure or piping per Faraday's law of electromagnetic induction and causes induction heating. Avoiding the induction coupling by increasing the clearance may not always be possible. However, it can be reduced by reducing ripple current itself or by placing a low-impedance shield such that induced current does not produce a overheating in the shield conductor as a result of lower resistance.

C. Instrumentation and Communication: Induced current in instrumentation cable causes noise. The ratio of signal to noise should be within acceptable level. The induction effect can be reduced by using shielded cable. 
D. Audible Noise: Changing ripple current causes the audible noise in metal laminations. Sometimes, the ripple frequency matches the natural frequency of the structure and magnifies the mechanical vibration noise. Mechanical noise can be reduced by damping or by reducing ripple current itself.

\section{RIPPLE CURRENT MITIGATION}

In most applications the effect of ripple current as mentioned in section II should be below a specified value. If the ripple current is above the specified value, it should be mitigated. Following are some of the ways to mitigate the ripple effect from dc output.

A. Increasing the pulse number of rectifier: Higher the number of pulses, lower is the ripple magnitude [4]-[5].

B. Using an Output Filter: If a capacitor is used across the load and an inductor is used in series with the load, the load current will be smoother and ripple effect will be lowered [6].

In this paper, ripple magnitude has controlled by the number of pulses. Higher the number of pulses, lower is the ripple magnitude. In a single-phase half-wave uncontrolled rectifier, the number of pulses is one. Likewise, in a single-phase full-wave uncontrolled rectifier, the number of pulses is two. It is shown in this paper that the ripple factor is 1.21 for a 1-pulse rectifier and 0.48 for a 2-pulse rectifier. To model the rectifier and to obtain voltage and current waveforms, a computer program called Alternative Transients Program (ATP) has been used [7]. Subsequently, 6-pulse, 12-pulse, and 18-pulse rectifiers will be modeled and advanced studies will be carried out. Use of output filter for ripple mitigation is left as a future work and is not presented in this paper.

\section{SINGLE-PHASE HALF-WAVE UNCOTROLLED RECTIFIER}

A single-phase half-wave uncontrolled rectifier feeding a resistive load is shown in Figure 1. The diode $\mathrm{D}$ conducts during the positive half cycle of supply voltage $\mathbf{V s}$ and stops conducting during negative halfcycle of the supply voltage forming a 1-pulse rectifier. Source current and load current are represented by $\mathrm{i}_{\mathrm{S}}$ and $\mathrm{i}_{0}$ respectively. $\mathbf{V}_{0}$ average output voltage.

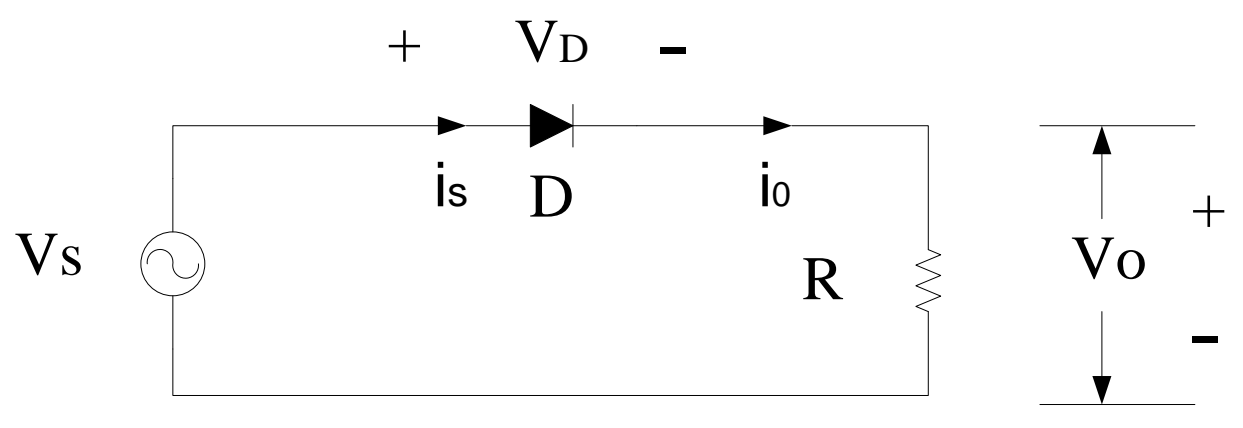

Figure 1. Single-phase half-wave uncontrolled rectifier with R load

The instantaneous value of $\mathbf{V s}$ is given by

(3)

$$
\mathrm{Vs}=\mathrm{V}_{\mathrm{m}} \sin \omega \mathrm{t}
$$

where $\mathrm{V}_{\mathrm{m}}=$ is the peak value of $\mathrm{Vs}$

Similarly, the instantaneous value of $\mathbf{V}_{0}$ is given by

$$
\mathrm{V}_{0}=\mathrm{V}_{\mathrm{m}} \sin \omega \mathrm{t}\{0 \text { to } \pi, 2 \pi \text { to } 3 \pi \text {, etc }\}
$$

And, the instantaneous value of voltage across diode $\mathbf{V}_{\mathrm{D}}$ is given by

(5)

$$
\mathrm{V}_{\mathrm{D}}=\mathrm{Vs}-\mathrm{V}_{0}=\mathrm{V}_{\mathrm{m}} \sin \omega \mathrm{t}\{\pi \text { to } 2 \pi, 3 \pi \text { to } 4 \pi \text {, etc }\}
$$

$$
\text { and, } \mathrm{i}_{0}(\omega \mathrm{t})=\mathrm{i}_{\mathrm{S}}(\omega \mathrm{t})=\mathrm{V}_{0} / \mathrm{R}=\left(\mathrm{V}_{\mathrm{m}} \sin \omega \mathrm{t}\right) / \mathrm{R}\{0 \text { to } \pi, 2 \pi \text { to } 3 \pi \text {, etc }\}+0\{\pi \text { to } 2 \pi, 3 \pi \text { to } 4 \pi \text {, etc }\}
$$

Voltage input waveform is shown in Figure 2. Output voltage and output currents are shown in Figure 3. 


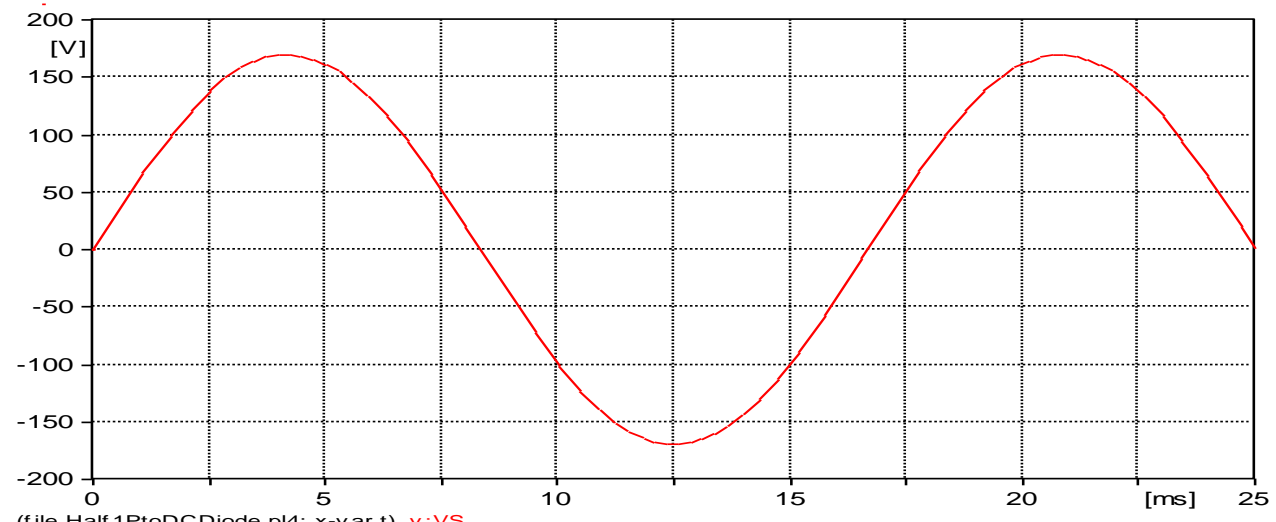

Figure 2. Supply voltage waveform

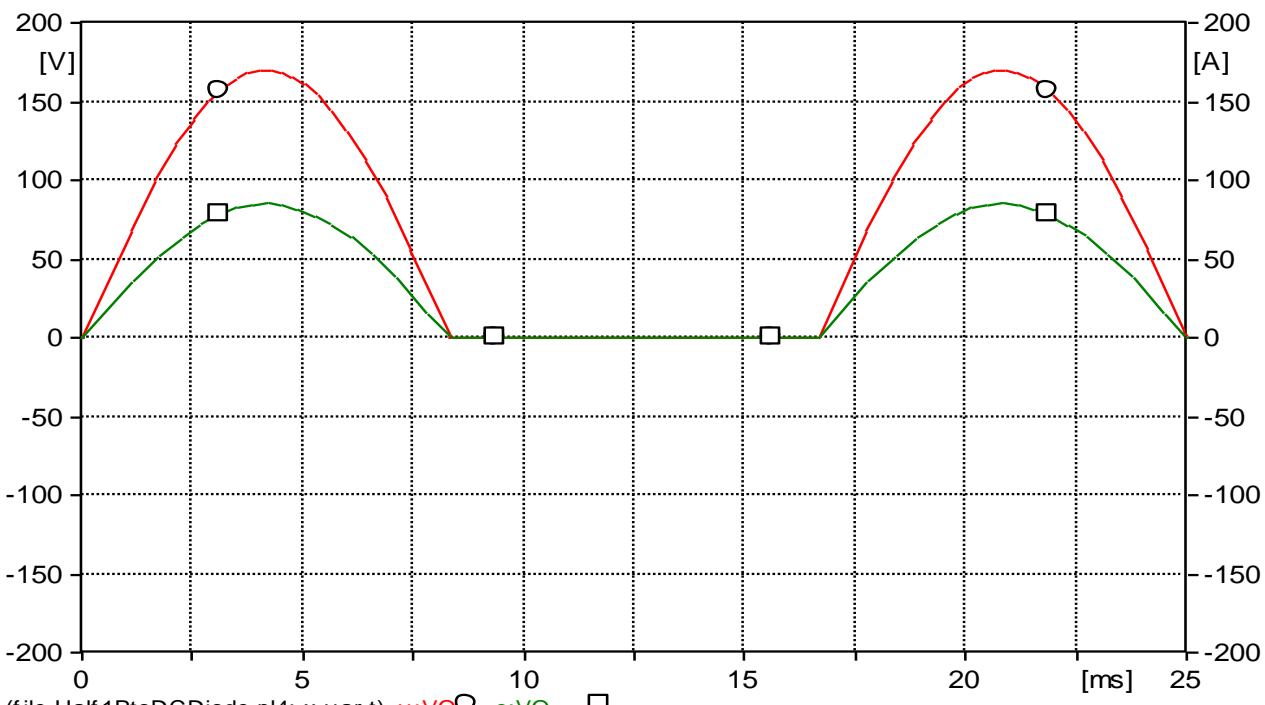

Figure 3. Half-wave Rectifier Output Voltage and Current

The average value $\mathbf{I}_{0}$ of the load current $\mathrm{i}_{0}(\omega \mathrm{t})$ which is periodic in $2 \pi$ is given by [8]-[10]

$$
\mathbf{I}_{0}=(1 / 2 \pi) \int_{0}^{2 \pi} \mathrm{i}_{0}(\omega \mathrm{t}) \mathrm{d} \omega \mathrm{t}
$$

(7)

After solving above equation we get, $\mathbf{I}_{0}=\mathrm{V}_{\mathrm{m}} /(\pi \mathrm{R})=\mathrm{I}_{\mathrm{m}} / \pi$

(8)

where $I_{m}$ is peak value of $i_{0}(\omega t)$

For the load current $\mathrm{i}_{0}(\omega \mathrm{t})$ periodic in $2 \pi$, the rms current can be given as [7]

(9)

$$
\mathbf{I}=\sqrt{ }\left[\frac{1}{2 \pi} \int_{0}^{2 \pi} \mathrm{i}^{2}{ }_{0}(\omega \mathrm{t}) \mathrm{d} \omega \mathrm{t}\right]
$$

(10)

$$
=\mathrm{V}_{\mathrm{m}} /(2 \mathrm{R})=\mathrm{I}_{\mathrm{m}} / 2
$$

It should be noted that the corresponding rms value of the load current for sinusoidal operation is $\mathrm{I}_{\mathrm{m}} / \sqrt{ } 2$.

Thus the degree of distortion, Ripple Factor, in a single-phase half-wave rectified current waveform can be calculated using equation (2).

$$
\begin{aligned}
& =\sqrt{ }\left[\left\{\left(\mathrm{I}_{\mathrm{m}} / 2\right) /\left(\mathrm{I}_{\mathrm{m}} / \pi\right)\right\}^{2}-1\right] \\
& =1.21
\end{aligned}
$$

If the output wave is perfectly dc, the ripple factor will be zero. Ripple factor of 1.21 is unacceptably high for many industrial applications.

\section{SINGLE-PHASE FULL-WAVE UNCOTROLLED RECTIFIER}


A single-phase full-wave uncontrolled rectifier feeding a resistive load is shown in Figure 4. Diodes D1 and D2 conduct during the positive half cycle of supply voltage Vs; and diodes D3 and D4 conduct during negative half-cycle of the supply voltage forming a 2-pulse rectifier. Source current and load current are represented by $i_{S}$ and $i_{0}$ respectively. $\mathbf{V}_{0}$ average output voltage. Output voltage and output currents are shown in Figure 5.

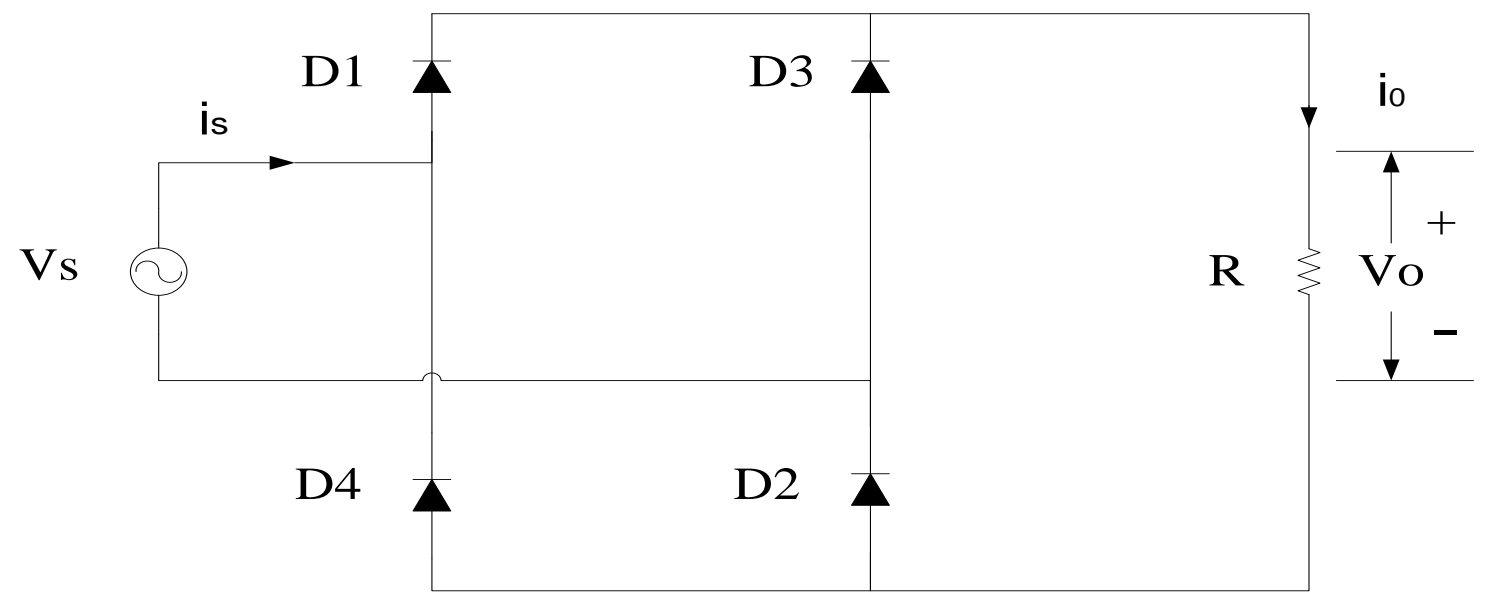

Figure 4. Single-phase full-wave uncontrolled rectifier with R load

The instantaneous value of load current can be given as,

$$
\mathrm{i}_{0}(\omega \mathrm{t})=\left[\mathrm{V}_{\mathrm{m}} \sin \omega \mathrm{t}\right] / \mathrm{R}\{0 \text { to } \pi, 2 \pi \text { to } 3 \pi \text {, etc }\}+\left[\mathrm{V}_{\mathrm{m}} \sin (\omega \mathrm{t}-\pi)\right] / \mathrm{R}\{\pi \text { to } 2 \pi, 3 \pi \text { to } 4 \pi \text {, etc }\}
$$

The average value $\mathbf{I}_{0}$ of the load current $\mathrm{i}_{0}(\Phi \mathrm{t})$ which is periodic in $2 \pi$ is given by [7]

(14)

$$
\mathbf{I}_{0}=(1 / 2 \pi) \int_{0}^{2 \pi} \mathrm{i}_{0}(\omega \mathrm{t}) \mathrm{d} \omega \mathrm{t}
$$

After solving above equation we get, $\mathbf{I}_{0}=2 \mathrm{~V}_{\mathrm{m}} /(\pi \mathrm{R})=2 \mathrm{I}_{\mathrm{m}} / \pi$

(15)

It can be seen that the average value of output current in case of full-wave rectifier is twice the value of in case of half-wave rectifier.

The rms value of the load current can be given as [7]

$$
\mathbf{I}=\sqrt{ }\left[\frac{1}{2 \pi} \int_{0}^{2 \pi} \mathrm{i}_{0}^{2}(\omega \mathrm{t}) \mathrm{d} \Phi \mathrm{t}\right]
$$

$$
=\mathrm{V}_{\mathrm{m}} /(\sqrt{ } 2 \mathrm{R})=\mathrm{I}_{\mathrm{m}} / \sqrt{2}
$$

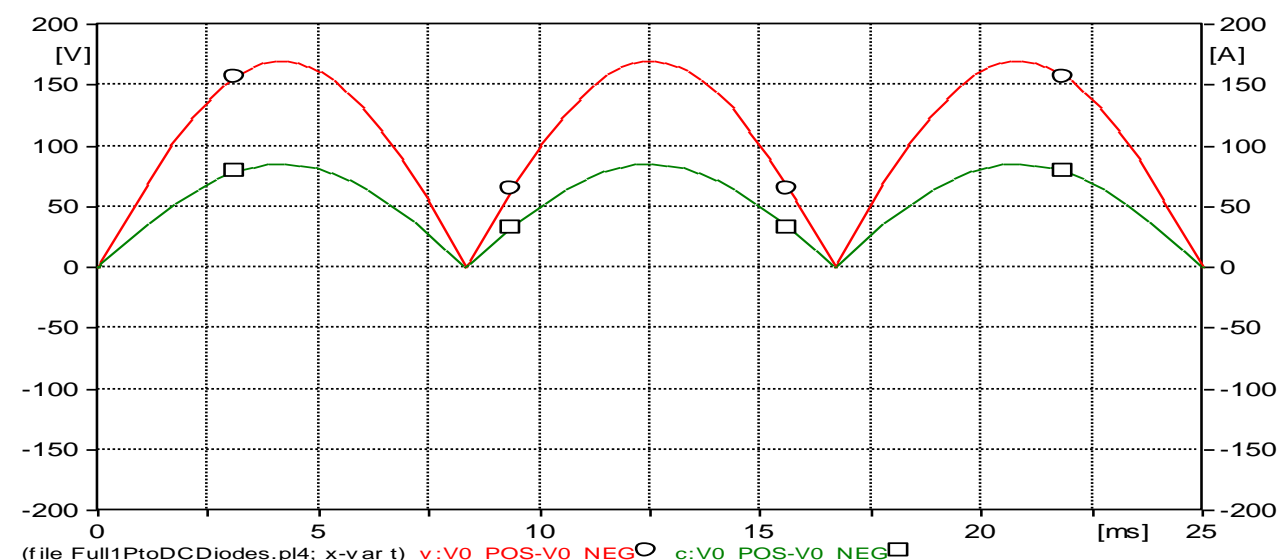

Figure 5. Full-wave Rectifier Output Voltage and Current

It should be noted that the corresponding rms value of the load current for half wave rectifier is $\mathrm{I}_{\mathrm{m}} / 2$. Thus the degree of distortion, Ripple Factor, in a single-phase full-wave rectified current waveform can be calculated using equation (2). 
(19)

$$
\begin{aligned}
& =\sqrt{ }\left[\left\{\left(\mathrm{I}_{\mathrm{m}} / \sqrt{ } 2\right) /\left(2 \mathrm{I}_{\mathrm{m}} / \pi\right)\right\}^{2}-1\right] \\
& =0.48
\end{aligned}
$$

Ripple factor of 0.48 is significantly better than that in half-wave rectifier with a ripple factor of 1.21.

\section{RESULTS}

The variation of average load current, rms load current, and ripple factor of load current are presented below in a tabular form.

\begin{tabular}{|c|c|c|}
\hline Property & Half-wave rectifier & Full-wave rectifier \\
\hline Average load current & $\mathrm{I}_{\mathrm{m}} / \pi=27 \mathrm{~A}$ & $2 \mathrm{I}_{\mathrm{m}} / \pi=54 \mathrm{~A}$ \\
\hline RMS load current & $\mathrm{I}_{\mathrm{m}} / 2=42.4 \mathrm{~A}$ & $\mathrm{I}_{\mathrm{m}} / \sqrt{2}=60 \mathrm{~A}$ \\
\hline Ripple factor of load current & $\sqrt{ }\left\{\left(\mathbf{I} / \mathbf{I}_{0}\right)^{2}-1\right\}=1.21$ & $\sqrt{ }\left\{\left(\mathbf{I} / \mathbf{I}_{0}\right)^{2}-1\right\}=0.48$ \\
\hline
\end{tabular}

\section{CONCLUSION}

Single-phase 2-pulse rectifier offered better ripple factor than a single-phase 1-pulse rectifier. The ripple factor was improved by $0.48 / 1.21=40 \%$. Theoretically, if the number of pulses is increased to infinity, the ripple factor will reduce to zero giving a perfect dc output. Subsequently, 6-pulse, 12-pulse, and 18-pulse rectifiers will be modeled and advanced studies will be carried out. This research will help seniors, graduate students, and design engineers to understand the modeling and working principle of ac to dc converters i.e. rectifiers.

\section{REFERENCES}

[1]. N. Mohan, T. M. Undeland, and W. P. Robbins, Power Electronics-Converters, Applications, and Design. USA: John Wiley \& Sons Inc, 1995, Chap. 5.

[2]. A. M. Trzynadlowski, Introduction to Modern Power Electronics. New Jersey: John Wiley \& Sons, Inc, 2010, Chap. 1.

[3]. M.Mazaheri, V. Scaini, and W. E. Veerkamp "Cause, Effects, and Mitigation of Ripple From Rectifiers," IEEE Trans. Industrial Application; vol. 39, no.4, pp. 1187-1192,July/August 2003

[4]. D. A. Paice, Power Electronic Converter Harmonics: Multipulse Methods for Clean Power. New York: IEEE Presss, 1996, Chap. 7.

[5]. B. Singh, G. Bhuvaneswari, V. Garg, and S. Gairola "Pulse Multiplication in AC-DC converters for Harmonic Mitigation in Vector-Controlled Induction Motor Drives," IEEE Trans. Energy Conversion; vol. 21, no. 2, pp.342-352, June 2006

[6]. M. Ramasubbamma, V. Madhusudhan, K. S. R. Anjaneyulul, and P. Sujatha "Design Aspect and Analysis for Higher Order harmonic Mitigation of Power Converter Feeding a Vector Controlled Induction Motor Drives," IEEE International Conference on Advances in Engineering, Science, and Management (ICAESM-2012), pp. 282-287, March 30, 31, 2012.

[7]. http://emtp.org accessed October 2012

[8]. W. Shepherd and L. Zhang, Power Converter Circuits. New York: Marcel Dekker, Inc, 2004, Chap. 2.

[9]. T. H. Barton, Rectifiers, Cycloconverters, and AC Controllers. New York: Oxford University Press, 1994, Chap. 2.

[10]. B. K. Bose, Power Electronics and Variable Frequency Drives-Technology and Application. New Jersey: IEEE Press, 1997, Chap. 3. 